\title{
$\mathrm{PH} 100$ accuaidad
}

\section{El Proyecto Patrimonio del Ayuntamiento de Aroche (Huelva) confirma la fórmula de la gestión local e integral}

\begin{abstract}
El Ayuntamiento de Aroche (Huelva) practica, desde hace 15 años, un modelo local de gestión integral del patrimonio teniendo en cuenta los cuatro pilares básicos de la cadena de valor: la investigación, la protección, la conservación y la socialización del patrimonio. Esta experiencia ha incidido directamente en el desarrollo socioeconómico y cultural del municipio de Aroche, con 3.109 habitantes. El Proyecto Patrimonio que aquí presentamos puede ser un ejemplo muy importante para la mejora de las condiciones de vida de las zonas rurales de interior y la lucha contra la despoblación.
\end{abstract}

Nieves Medina Rosales | Ayuntamiento de Aroche

Url de la contribución <www.iaph.es/revistaph/index.php/revistaph/article/view/4598>

Aroche es un municipio de 3.109 habitantes, ubicado al norte de la provincia de Huelva, en la frontera con Portugal. Esta posición fronteriza ha condicionado la historia de este territorio, cuya ocupación está documentada desde el Neolítico. Más de 100 yacimientos arqueológicos han sido catalogados en su término municipal, destacando la ciudad romana de Arucci Turobriga, o la singularidad de su conjunto histórico, con el castillo almohade, la muralla medieval-moderna, la iglesia de la Asunción (s. XV) y el convento de la Cilla (s. XVII), que alberga el centro de recepción de visitantes, la colección arqueológica municipal, el museo del Rosario y el punto de información del parque natural.

En 2004 el Ayuntamiento de Aroche toma la importante decisión de desarrollar un proyecto municipal bajo la denominación de Proyecto Patrimonio destinado a investigar, proteger, conservar y socializar el importante patrimonio histórico-arqueológico del municipio (MEDINA ROSALES, MUÑIZ CARRASCO, 2010; MEDINA ROSALES, MEDINA ROSALES, 2018a; 2018b). El estado de conservación del patrimonio arocheno en 2003 resultaba ciertamente preocupante, ruinoso, debido a la falta de mantenimiento y de políticas de intervención sobre el patrimonio.

Los inicios del proyecto contemplaron un período de reflexión y de conocimiento de experiencias similares. Fueron Mértola en Portugal y Almedinilla en Córdoba los lugares elegidos como referentes a seguir, adap-

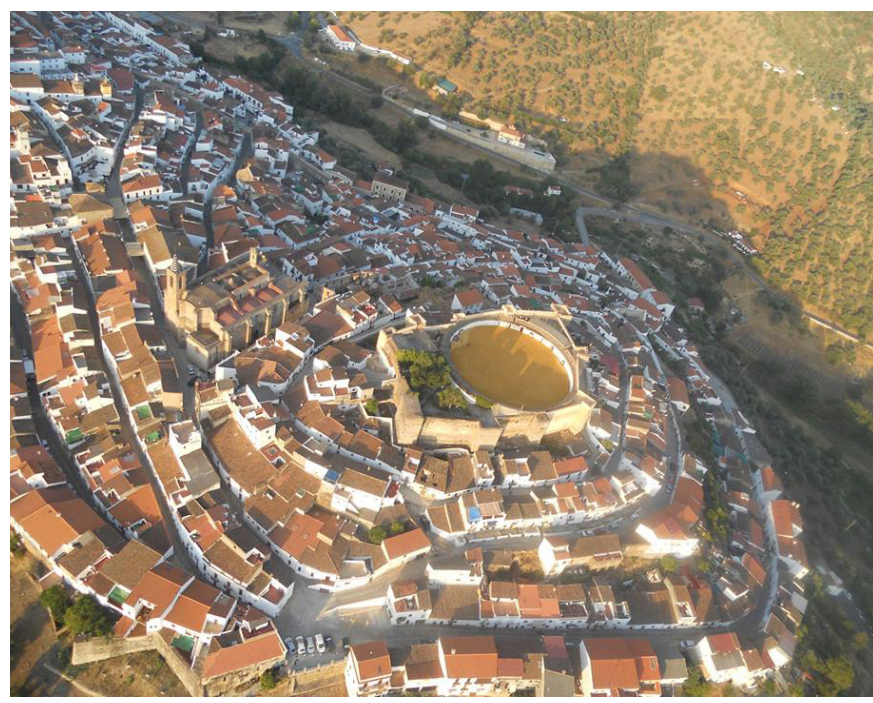

Vista aérea del conjunto histórico de Aroche | foto Ayuntamiento de Aroche

tando las experiencias al caso particular de Aroche. Mértola cuenta con más de cuarenta años de experiencia (GÓMEZ MARTÍNEZ, 2017; GÓMEZ MARTíNEZ; RAFAEL; TORRES, 2016) y es un referente nacional e internacional. Almedinilla en el extremo oriental de la comarca de la Subbética Cordobesa fue el segundo de los ejemplos a seguir (MUÑIZ JAÉN, 2002; 2007). Municipios de pequeño tamaño, rurales y con proyectos destinados a gestionar el patrimonio desde una perspectiva nueva, compleja, vinculada al desarrollo rural, al respeto, al equilibrio, a la recuperación de la identidad local, a la fijación de la población, al desarrollo de la economía local, etc. 
El Proyecto Patrimonio de Aroche se concibió como un modelo de gestión integral del patrimonio, planificándose actuaciones y medidas a corto, medio y largo plazo. La financiación del proyecto ha sido variada, destacando los fondos propios, que atienden uno de los trabajos más constantes e importantes en la gestión del patrimonio, el mantenimiento diario. Las intervenciones y actuaciones han contado igualmente con aportaciones de fondos propios, combinadas con fondos provinciales, autonómicos, nacionales y fondos europeos. Con el paso de los años a estos fondos también se han sumado la Fundación Cajasol y una empresa local que ejerce un mecenazgo sobre el enclave arqueológico. Además, es necesario resaltar la colaboración absoluta del Área de Arqueología de la Universidad de Huelva, sobre todo en lo que al proyecto de Arucci Turobriga se refiere, yacimiento en el cual se está desarrollando un proyecto modélico de investigación, conservación y puesta en valor (CAMPOS CARRASCO, J. M.; MEDINA ROSALES, N.; BERMEJO MELÉNDEZ, 2017).

Dentro del Proyecto Patrimonio se realizan desde 2004 campañas de sensibilización hacia colectivos, escolares y trabajadores de las distintas actuaciones, como una forma de acercar el patrimonio al vecindario y que lo entendieran como parte de su identidad local y cultural. La gestión del proyecto se realiza desde la Oficina Municipal de Urbanismo y Patrimonio, creada en 2004 y dotada con un arquitecto, dos arquitectos técnicos, un arqueólogo, un licenciado en derecho y un administrativo, además del personal de obras.

El desarrollo del proyecto puede dividirse en dos fases diferenciadas. Una primera de inicio, entre 2004 y 2007 , con actuaciones significativas y campañas de sensibilización, y la preparación de lo que serían los proyectos enmarcados en la segunda fase a la que denominamos "fase de madurez". En esta segunda fase, además del desarrollo de importantes actuaciones sobre el patrimonio, se han creado eventos culturales vinculados a cada uno de los principales elementos que conforman el patrimonio histórico-arqueológico arocheno. Así, en el castillo se ha creado la Noche de las Velas, una noche mágica donde el castillo se ilumina con miles de velas, y hay música, teatro y recreaciones históricas. La torre de

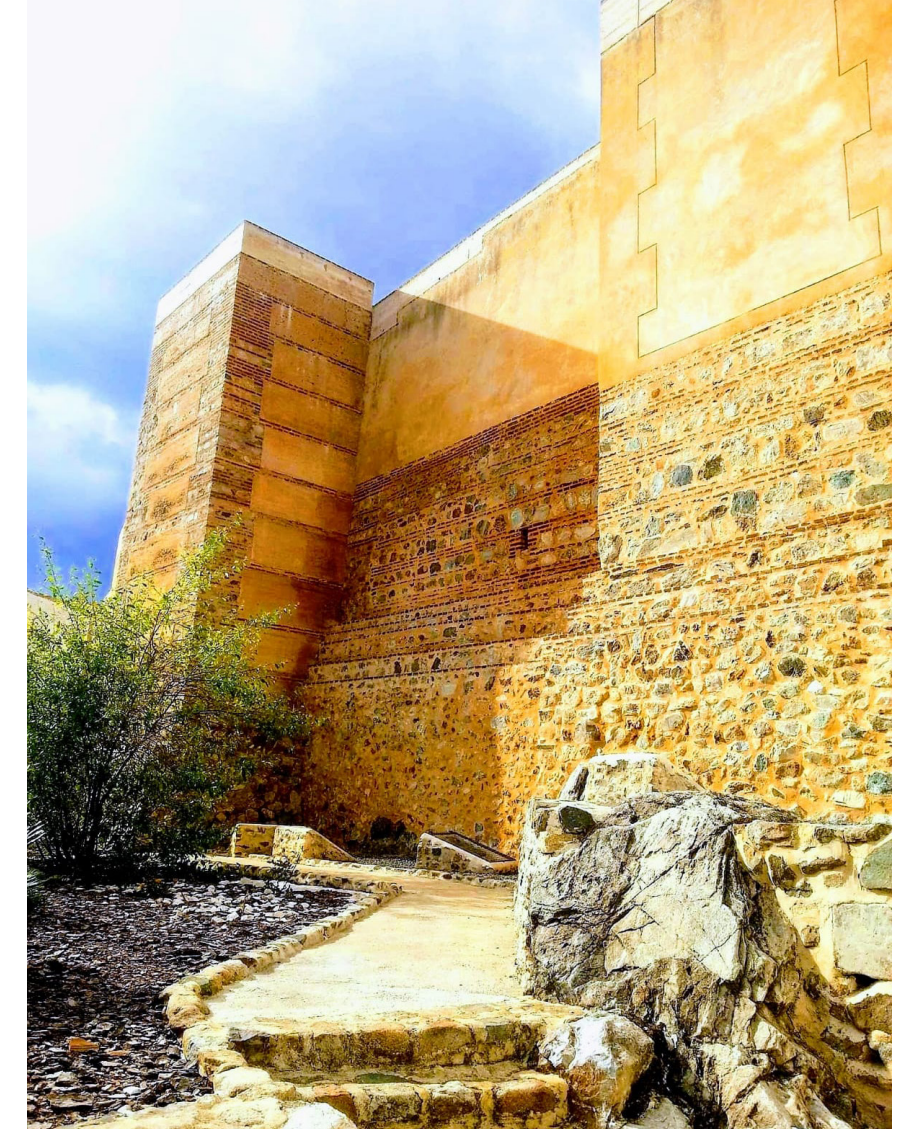

Vista de los espacios recuperados anexos al castillo | foto Nieves Medina

la San Ginés se convierte en el escenario de las Noches de la Almena, con cante y baile flamenco. La plaza de la iglesia acoge el Certamen de Bandas de Música, además de conciertos de diversa tipología o recreaciones históricas durante el Festival de Diana. Y es este último evento, el Festival de Diana, el que más ha incidido en la sensibilización hacia el patrimonio y en la participación ciudadana y en el turismo. En estas jornadas de cultura romana se recupera por dos días la vida cotidiana de Arucci, con rigor histórico y la participación de numerosas asociaciones de recreación histórica andaluzas y extremeñas. El Ayuntamiento ha creado en torno a este evento el Grupo Municipal de Recreación Histórica Baebia Aruccitana, con más de un centenar de arochenos. Dentro del Aula Municipal de Música, se ha creado una asignatura de música, danza y cultura romana, que da apoyo a la sección musical del grupo de recreación. Esto ha conseguido que una parte importante de los habitan- 


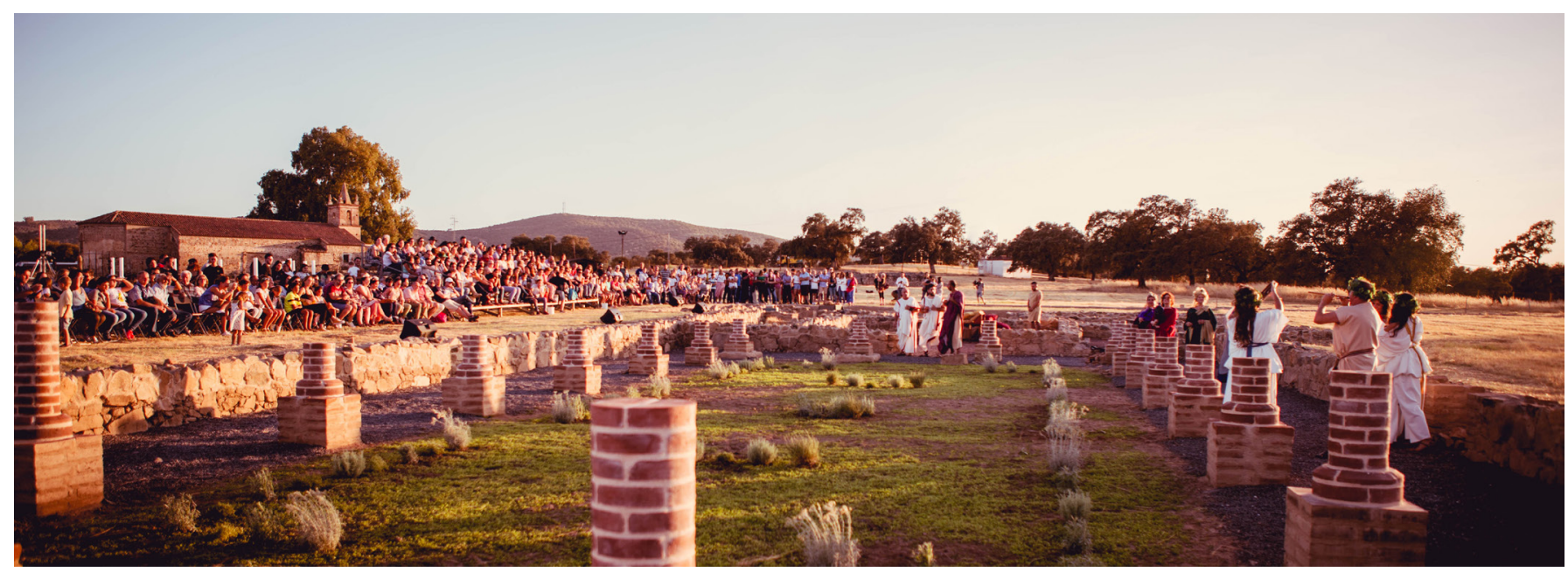

Vista de la celebración del Festival de Diana en la ciudad romana de Arucci Turobriga | foto Tomasz Palluch

tes de Aroche se sientan orgullosos de su patrimonio, que participen de su historia, que la muestren al público y que además se genere turismo, economía y, sobre todo, cultura.

Desde el inicio en 2004 del Proyecto Patrimonio se han realizado más de 100 intervenciones entre excavaciones arqueológicas, prospecciones geofísicas, restauración de 8 tramos de la muralla de la Villa, restauración del castillo, restauración de los frescos de la ermita de San Mamés, restauración de la Iglesia de la Asunción y de la torre de San Ginés, derribos de viviendas adosadas al castillo y muralla, creación de espacios públicos colindantes a estos monumentos, soterramiento de cableado aéreo, semisoterramiento de contenedores de residuos urbanos, empedrados tradicionales de calles, impermeabilizaciones de cubiertas de edificios históricos, etc. Además todo este patrimonio está abierto al público desde 2004 con horarios estables, visitas guiadas y eventos. En 2018 el proyecto Patrimonio de Aroche fue reconocido con el premio Sísifo de Patrimonio, otorgado por la Universidad de Córdoba, el Grupo de Investigación Sísifo y la Asociación Cultural Arqueología Somos Todos.

El Proyecto Patrimonio es un modelo de gestión del patrimonio desde el ámbito municipal desarrollado con recursos limitados pero constantes, y sobre todo con mucho respeto y sentido del deber de conservar estos elementos que forman parte de nuestra historia, de nuestra identidad colectiva y que deben formar parte de nuestro futuro. Ese futuro amenazado por la despoblación de las zonas rurales de interior pasa por la búsqueda de alternativas para el desarrollo socioeconómico y cultural. Las administraciones y la sociedad tenemos el deber de conservar y legar a las generaciones futuras nuestra historia y nuestro patrimonio, pero nada de esto quedará si abandonamos las zonas rurales. Con el despoblamiento del mundo rural no solo está amenazada una forma de vida, sino todo lo que esta contiene, incluido el patrimonio.

\section{Proyecto Patrimonio en datos}

> Más de 100 intervenciones sobre el patrimonio.

> Más de 100 integrantes en el grupo municipal de recreación histórica.

$>167$ plazas disponibles en alojamientos turísticos.

$>11 ' 10 \%$ de tasa media de paro en 2019 (21\% en 2015).

$>67$ '6\% de aumento del turismo de 2005 a 2018 (13.000 visitas guiadas en 2018, y entre 25.000 y 30.000 turistas anuales).

$>$ Creación de 7 puestos de trabajo estables.

> Como referencia entre 2012 y 2018 se contabilizaron más de 300 contratos temporales vinculados al Proyecto Patrimonio y una inversión de más de $400.000 €$.

$>80 \%$ de aumento en las actividades culturales. 


\section{BIBLIOGRAFÍA}

- CAMPOS CARRASCO, J. M.; MEDINA ROSALES, N.; BERMEJO MELÉNDEZ, J. (2017) El modelo de investigación y gestión de la ciudad romana de Arucci (Aroche, Huelva). En VAQUERIZO GIL, D.; RUIZ OSUNA, A. B.; DELGADO TORRES, M. (coord.) RESCATE, del registro estratigráfico a la sociedad del conocimiento: el patrimonio arqueológico como agente de desarrollo sostenible. Vol. 1. Córdoba: Universidad de Córdoba, 2017, pp. 189-206

- GÓMEZ MARTíNEZ, S. (2017) Mertola, villa museu. Un proyecto cultural de desarrollo. En VAQUERIZO GIL, D.; RUIZ OSUNA, A. B.; DELGADO TORRES, M. (coord.) RESCATE, del registro estratigráfico a la sociedad del conocimiento: el patrimonio arqueológico como agente de desarrollo sostenible. Vol. 1. Córdoba: Universidad de Córdoba, 2017, pp. 269-286

- gÓMEZ MARTíNEZ, S.; RAFAEL, L.; TORRES, C. (2016) Mértola Vila Museu: um projecto arqueológico de desenvolvimento integrado. Revista de Arqueología Pública, vol. 10, n. $^{\circ} 3,2016$, pp. 55-80

- MEDINA ROSALES, N. (2018a) La gestión integral del patrimonio histórico-arqueológico desde el ámbito municipal: el caso de Aroche. En CAMPOS JARA, P. (ed.) Arqueología y Territorio en la provincia de Huelva. Veinte años de las Jornadas de Aljaraque (1998-2017). Huelva: Diputación Provincial de Huelva, Servicio de Publicaciones, 2018, pp. 515-538

- MEDINA ROSALES, N. (2018b) Gestión municipal del patrimonio histórico-arqueológico de Aroche: 10 años de desarrollo del Proyecto Patrimonio, 2004-2014. En Actas del VIII Encontro de Arqueologia do Sudoeste Peninsular. Serpa: Cámara de Serpa, 2018, pp. 957-1012

- MUÑIZ CARRASCO, A.; MEDINA ROSALES, N. (2010) Gestión municipal del patrimonio histórico arqueológico: el caso de Aroche. En CARRASCO, FRANCISCO (DEL); SANTOS GÓMEZ, N. (coord.) XXII Jornadas de Patrimonio de la Comarca de la Sierra, Higuera de la Sierra (Huelva). Huelva: Diputación Provincial de Huelva, 2010, pp. 97-116

- MUÑIZ JAÉN, I. (2002) El Ecomuseo del Río Caicena en Almedinilla-Córdoba: un proyecto de desarrollo social, cultual y económico desde el patrimonio histórico y natural. En Actas de IV Jornadas Andaluzas de Difusión del patrimonio histórico. Sevilla: Consejería de Cultura de la Junta de Andalucía, 2002, pp 205-227

- MUÑIZ JAÉN, I. (2007) El proyecto municipal del Ecomuseo del Río Caicena (Almedinilla, Córdoba): Patrimonio y desarrollo local desde el mundo rural. E-rph [en línea], n. ${ }^{\circ}$ 1, 2007 <https://revistaseug.ugr.es/index.php/erph/article/view/3322> [Consulta: 15/04/2020]

- TORRES, C. (2003) Campo Arqueológico de Mértola (Portugal). Incentivar un turismo rural a escala humana. Revista $P H$ [en línea], n. ${ }^{\circ} 42,2003<$ http://www.iaph.es/revistaph/index. php/revistaph/article/view/1491> [Consulta: 15/04/2020] 